\title{
Efficient Adsorption Performance of Lithium Ion onto Cellulose Microspheres with Sulfonic Acid Groups
}

\author{
Chenxi Xu ${ }^{1}$, Tianlin Yu ${ }^{1}$, Jing Peng ${ }^{1, *} \mathbb{C}$, Long Zhao ${ }^{2}$, Jiuqiang $\mathrm{Li}^{1}$ and Maolin Zhai ${ }^{1, *}$ \\ 1 Beijing National Laboratory for Molecular Sciences, Radiochemistry and Radiation Chemistry Key \\ Laboratory of Fundamental Science, the Key Laboratory of Polymer Chemistry and Physics of Ministry of \\ Education, College of Chemistry and Molecular Engineering, Peking University, Beijing 100871, China; \\ 1501110336@pku.edu.cn (C.X.); yutianlin@bnds.cn (T.Y.); jqli@pku.edu.cn (J.L.) \\ 2 State Key Laboratory of Advanced Electromagnetic Engineering and Technology, School of Electrical and \\ Electronic Engineering, Huazhong University of Science and Technology, Wuhan 430074, China; \\ zhaolong@hust.edu.cn \\ * $\quad$ Correspondence: jpeng@pku.edu.cn (J.P.); mlzhai@pku.edu.cn (M.Z.); Tel.: +86-10-6275-7193 (J.P.); \\ +86-10-6275-3794 (M.Z.); Fax: +86-10-6275-3794 (M.Z.)
}

Received: 29 December 2019; Accepted: 20 January 2020; Published: 3 February 2020

check for updates

\begin{abstract}
The separation of $\mathrm{Li}^{+}$from an aqueous solution has received much attention in recent years because of its wide application in batteries and nuclear energy. A cellulose microsphere adsorbent with sulfonic acid groups (named as CGS) was successfully prepared by the pre-irradiation-induced emulsion graft polymerization of glycidyl methacrylate onto cellulose microspheres through subsequent sulfonation and protonation. The adsorption performance of $\mathrm{Li}^{+}$onto the CGS adsorbent is investigated in detail. The as-prepared CGS adsorbent exhibited fast adsorption kinetics and a high adsorption capacity of $\mathrm{Li}^{+}(16.0 \mathrm{mg} / \mathrm{g})$ in a wide $\mathrm{pH}$ range from 4 to 10 . The existence of $\mathrm{K}^{+}$and $\mathrm{Na}^{+}$was found to have the ability to affect the adsorption capacity of $\mathrm{Li}^{+}$due to the cation-exchange adsorption mechanism, which was further confirmed by X-ray photoelectron spectroscopy (XPS). The column adsorption experiment indicated that the adsorption capacity of CGS agreed well with the batch adsorption, and a fast desorption could be obtained in $10 \mathrm{~min}$. It is expected that CGS has potential usage in the adsorption separation of $\mathrm{Li}^{+}$from an aqueous solution.
\end{abstract}

Keywords: $\quad \mathrm{Li}^{+}$adsorption; cellulose microsphere adsorbent; radiation synthesis; ion-exchange mechanism

\section{Introduction}

Lithium has been widely studied in recent decades due to its wide applications in lithium secondary batteries [1], catalysts [2], and nuclear energy [3]. It is important to separate lithium from brine and to recover lithium from a spent solution by using an environmentally-friendly, simple, and low cost method [4]. Among the processes for lithium separation, such as adsorption, solvent extraction [5,6], precipitation [7] and electrochemical methods [8,9], the adsorption process is considered to be a promising method to separate lithium at a large scale with a high efficiency.

Several adsorbents such as lithium manganese oxides (LMOS), ion sieves, $\mathrm{H}_{2} \mathrm{TiO}_{3}$ [10], and ion-imprinted polymers [11] have been prepared for the adsorption of lithium. Among them, the most common inorganic adsorbents are the LMOS [12-14] and ion sieves, which have good adsorption capacities and selectivities [15]. However, these adsorbents with powder forms cannot be practically used due to the loss of adsorbents in their applications [16,17]. To overcome this disadvantage, an ion-sieve powder has been immobilized onto polymers such as membranes [16], foams [18], fibers and spheres [19] by using poly(vinyl chloride), polyacrylonitrile, poly(vinylidene fluoride) 
and polyacrylamide as binders. Nevertheless, these materials still have some weaknesses such as slow adsorption kinetics, complicated synthetic routes and non-biodegradability, which limit their practical application.

Thus, it is important to develop an environmentally-friendly adsorbent with a high adsorption capacity, fast adsorption kinetics, good biodegradability, and reusability. A microcrystalline cellulose microsphere (CMS) is a suitable substrate for adsorbents due to its good biodegradability, renewability, low cost [20], and spherical morphology. However, due to the low adsorption capacity of $\mathrm{Li}^{+}$onto raw cellulose, some functional groups should be introduced to enhance its adsorption performance. Radiation-induced graft polymerization is a convenient way to modify polymer materials with a certain shape [21-23] and has been proven as a green, fast, effective, and environmentally-friendly method in the modification of cellulose [24-29]. Some research about the radiation grafting of glycidyl methacrylate (GMA) onto cellulose has been reported in literatures [26,28,30]. Recently, cellulose microspheres that contained crown-ether groups were synthesized via gamma-radiation-induced grafting in our previous work, and this crown-ether modified CMS could be used to selectively separate lithium-ions and their isotopes [31]; however, the adsorbent in this method has a low adsorption uptake for $\mathrm{Li}^{+}$in an aqueous solution. In order to separate the $\mathrm{Li}^{+}$from an aqueous solution, we used a cellulose microsphere adsorbent with sulfuric acid (named CGS) [27] that was prepared through the pre-irradiation-induced emulsion grafting of the GMA onto the CMS, followed by a sulfonation and protonation reaction. We found that the cations of ionic liquids can be efficiently adsorbed onto CGS by an ion exchange mechanism [27]. Thus, CGS is expected to be good adsorbent for $\mathrm{Li}^{+}$. In this work, the kinetics and isotherm of the adsorption of $\mathrm{Li}^{+}$onto CGS in an aqueous solution are investigated and compared with the commercial cation exchange resin, DIAION SK1B resin. Additionally, the effects of the solution's $\mathrm{pH}$ and the presence of various cations and anions on the adsorption performance are studied in detail. Furthermore, the adsorption mechanism was investigated by $\mathrm{X}$-ray photoelectron spectroscopy (XPS), the reusability of the CGS adsorbent was studied in five consecutive circles, and column adsorption was measured to test its feasibility in column separation of $\mathrm{Li}^{+}$from the aqueous solution, the results of all of which are analyzed herein.

\section{Materials and Methods}

\subsection{Materials and Reagents}

CMSs with an average particle size of $230 \mu \mathrm{m}$ were obtained from Asahi Kasei Chemicals Corporation, Japan. DIAION SK1B resins (a commercial cation exchange resins containing a sulfonic group) were obtained from Mitsubishi Chemicals Corporation, Japan. Glycidyl methacrylate, LiSCN, and $\mathrm{LiCl}$ (purity $>99 \%$ ) were purchased from J\&K Company (Beijing, China). All the other chemicals were analytical grade and used without further purification, and tri-distilled water was used throughout the experiments.

\subsection{Instruments and Characterization}

The content of S in CGS was obtained in an elemental analyzer (Thermo Flash EA 1112, Waltham, MA, USA). Micro-FTIR analyses of the CMS, CGG (cellulose microspheres grafted by GMA) and CGS were performed with a Nicolet (Magna-IR 750, Waltham, MA, USA) spectrometer. The spectra were recorded in the absorbance mode in the wavenumber range of $4000 \sim 600 \mathrm{~cm}^{-1}$. XPS experiments were carried out on an AXIS-Ultra instrument (Krato Analytical, Manchester, UK) with the use of monochromatic $\mathrm{Al} \mathrm{K} \alpha$ radiation $(225 \mathrm{~W}, 15 \mathrm{~mA}$, and $15 \mathrm{kV}$ ) and low energy electron flooding for charge compensation. All data were analyzed with the CASA XPS software. The morphology of the dried CMS, CGG and CGS samples were observed with scanning electron microscopy (SEM) (Hitachi S-4800, Tokyo, Japan) at an accelerating voltage of $1 \mathrm{kV}$ after gold coating. 


\subsection{Preparation of CGS}

The adsorbent was prepared according to our previous work [27], and its synthetic route is illustrated in Scheme 1.
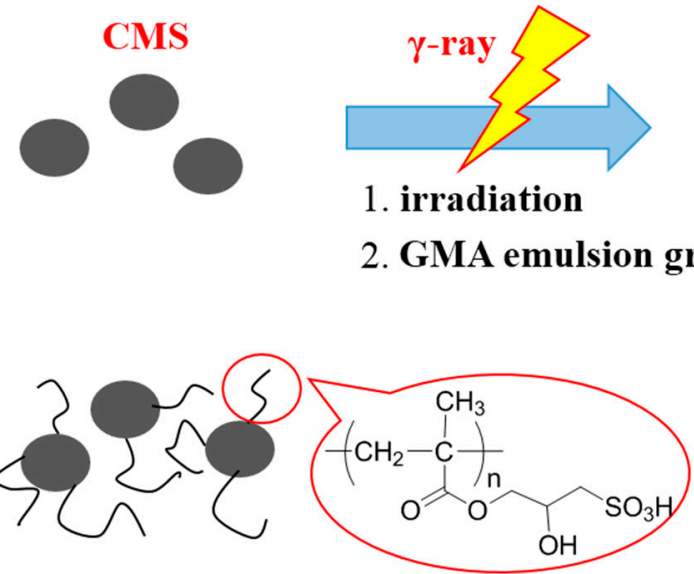

\section{CGS adsorbent}

Scheme 1. The synthetic route of the CGS (cellulose microsphere adsorbent with sulfuric acid) adsorbent.

\subsubsection{Radiation-Induced Emulsion Grafting of GMA onto Cellulose Microspheres}

In the grafting step, $1.0 \mathrm{~g}$ of a dried CMS was irradiated in air with gamma ray from a ${ }^{60} \mathrm{Co}$ source (Peking University, Beijing, China) at a dose rate of $380 \mathrm{~Gy} / \mathrm{min}$ for $20 \mathrm{kGy}$ (which was traced by a Fricke dosimeter). Then, the irradiated CMS was immersed into a $5 \mathrm{wt} \%$ GMA aqueous emulsion (with $0.5 \mathrm{wt} \%$ Tween 20). After being bubbled with Ar to get rid of $\mathrm{O}_{2}$, the grafting reaction was carried out in a shaker at $50{ }^{\circ} \mathrm{C}$ and $140 \mathrm{rpm}$ for a period of time. The residual monomer and homo-polymer were removed by washing with acetone and water for three times, respectively. The as-prepared microspheres were then dried in a vacuum at $45^{\circ} \mathrm{C}$ to a constant weight, and cellulose microspheres grafted by the GMA are named CGG. The degree of grafting (DG) was calculated as follows:

$$
\mathrm{DG}(\%)=\frac{W_{\mathrm{g}}-W_{0}}{W_{0}} \times 100
$$

where $W_{0}$ and $W_{\mathrm{g}}$ are the weights of the initial cellulose microspheres and dried grafted cellulose microspheres, respectively.

CGGs with different DG values (26\% and $63 \%$ ) were prepared with varying reaction times and used for further chemical modification.

\subsubsection{Chemical Modification of CGG}

Typically, $1.0 \mathrm{~g}$ of the CGG was added into a solution containing $1.26 \mathrm{~g}$ of $\mathrm{Na}_{2} \mathrm{SO}_{3}, 1.89 \mathrm{~g}$ of 2-propanol, and $9.45 \mathrm{~g}$ of $\mathrm{H}_{2} \mathrm{O}$, and the reaction was carried out in a shaker $(120 \mathrm{rpm})$ at $50{ }^{\circ} \mathrm{C}$ for $20 \mathrm{~h}$. The sulfonated microspheres were separated and washed with water three times. The protonation of the microspheres was then carried out by using $50 \mathrm{~mL}$ of $2 \mathrm{~mol} / \mathrm{L} \mathrm{H}_{2} \mathrm{SO}_{4}$ in a shaker $(120 \mathrm{rpm})$ at $50{ }^{\circ} \mathrm{C}$ for $4 \mathrm{~h}$. The resulting samples were washed with distilled water, followed by acetone. Finally, the CGS was obtained by drying to a constant weight in a vacuum oven.

CGGs with DG values of $26 \%$ and $63 \%$ were used for sulfonation and protonation, and the corresponding products were named as CGS-I and CGS-II, respectively.

\subsection{Adsorption of $\mathrm{Li}^{+}$onto CGS Adsorbents and DIAION SK1B Resin}

Adsorption experiments were carried out in a flask that contained $20 \mathrm{mg}$ of adsorbents and $20 \mathrm{~mL}$ of the $\mathrm{Li}^{+}$solution. The flask was then placed in a shaker at $30^{\circ} \mathrm{C}$ and $140 \mathrm{rpm}$ for a period of time. 
The $\mathrm{Li}^{+}$concentration was analyzed at a certain time interval by inductively coupled plasma-atomic emission spectrometry (ICP-AES, Prodigy, America) at $30^{\circ} \mathrm{C}$. The standard deviation of the test results given by the ICP-AES was within $3 \%$. The $\mathrm{Li}^{+}$uptake was calculated as follows:

$$
\mathrm{Li}^{+} \text {uptake }=\left(c_{0}-c_{\mathrm{e}}\right) \times \frac{V}{m}
$$

where $c_{0}$ and $c_{\mathrm{e}}$ are the $\mathrm{Li}^{+}$concentrations before and after adsorption, respectively; $V$ is the volume of the aqueous solution used for adsorption; and $m$ is the weight of the added CGS adsorbents.

The adsorption time was set as $12 \mathrm{~h}$ except for the samples in the kinetics study, and the concentration of the $\mathrm{Li}^{+}$was fixed at $140 \mathrm{ppm}$ except for the samples in the adsorption isotherm, where the concentration was varied. The lithium salt was $\mathrm{LiCl}$ unless otherwise stated. A solution with $\mathrm{pH}$ of 10 was used in all experiments except for the study of the influence of $\mathrm{pH}$.

\subsection{Regeneration of the Adsorbent}

After adsorption, the residual solution was removed, and $20 \mathrm{~mL}$ of a $1 \mathrm{~mol} / \mathrm{L} \mathrm{HCl}$ solution was added to the flask, followed by $24 \mathrm{~h}$ of shaking in the shaker at $30^{\circ} \mathrm{C}$ and $140 \mathrm{rpm}$. Then, the adsorbents were washed three times with water. The adsorption and desorption experiments were conducted in five consecutive circles. The adsorption experiments were carried out by a very similar procedure to that shown in Section 2.4.

\subsection{Column Adsorption}

The column adsorption was carried out at $25^{\circ} \mathrm{C} .1 .30 \mathrm{~g}$ of CGS-II was swelled in water and then poured into a glass column $(l=101 \mathrm{~mm}, d=5.32 \mathrm{~mm})$. In the absorption experiment, an $\mathrm{Li}_{2} \mathrm{SO}_{4}$ solution $\left(C_{\mathrm{i}}=19.8 \mathrm{ppm} \mathrm{Li}\right)$ was pumped into the column at $2.0 \mathrm{~mL} / \mathrm{min}$. The $\mathrm{Li}^{+}$concentration of the effluent $\left(C_{t}\right)$ was measured by using ICP-AES at a premeditated schedule to get a complete breakthrough curve. In the desorption experiment, the Li-loaded column was first washed with deionized water to remove unbound $\mathrm{Li}^{+}$, followed by the addition of $1 \mathrm{~mol} / \mathrm{L} \mathrm{HCl}$ at $2.0 \mathrm{~mL} / \mathrm{min}$ to get the desorption curve.

\section{Results and Discussions}

\subsection{Preparation of the CGS Adsorbents}

When the CMS was irradiated by ${ }^{60} \mathrm{Co}$ gamma ray in air, trapped free radicals were generated in the crystalline area of cellulose, and peroxides were also formed in the amorphous phase of cellulose due to the presence of oxygen [32], which is very suitable for the grafting of a monomer [24]. When heated at $50{ }^{\circ} \mathrm{C}$, the radicals trapped inside the crystalline phase of cellulose migrated to the surface and initiated the graft copolymerization of the GMA, forming the grafting chains on the cellulose microspheres. The CGGs with DG values of $26 \%$ and $63 \%$ were prepared by controlling the grafting reaction time.

\subsection{Characterizations of the CGS Adsorbents}

\subsubsection{FTIR and XPS Analysis}

Both FTIR and XPS were used to investigate the change in the chemical structures of different samples. The micro-FTIR spectra of the CMS, CGG and CGS are shown in Figure 1A. After the pre-irradiation-induced emulsion grafting of GMA, a strong peak at wavenumber $1731 \mathrm{~cm}^{-1}$ in the CGG was found that corresponded to the characteristic absorption peak of a $\mathrm{C}=\mathrm{O}$ group in the poly(glycidyl methacrylate) (PGMA). Moreover, the bands at 1258 and $909 \mathrm{~cm}^{-1}$ were also attributed to the epoxy group in the PGMA, indicating a successful grafting of the PGMA onto the CMS. For the CGS, a new peak at $1043 \mathrm{~cm}^{-1}$ appeared that was assigned to the $S=O$ group, and the intensity of the epoxy group at $909 \mathrm{~cm}^{-1}$ decreased, thus indicating the ring-opening reaction of the PGMA in the 
CGG. The results were similar to those of our previous report [27]. Micro-FTIR results confirmed a successful synthesis of the CGG and the CGS.
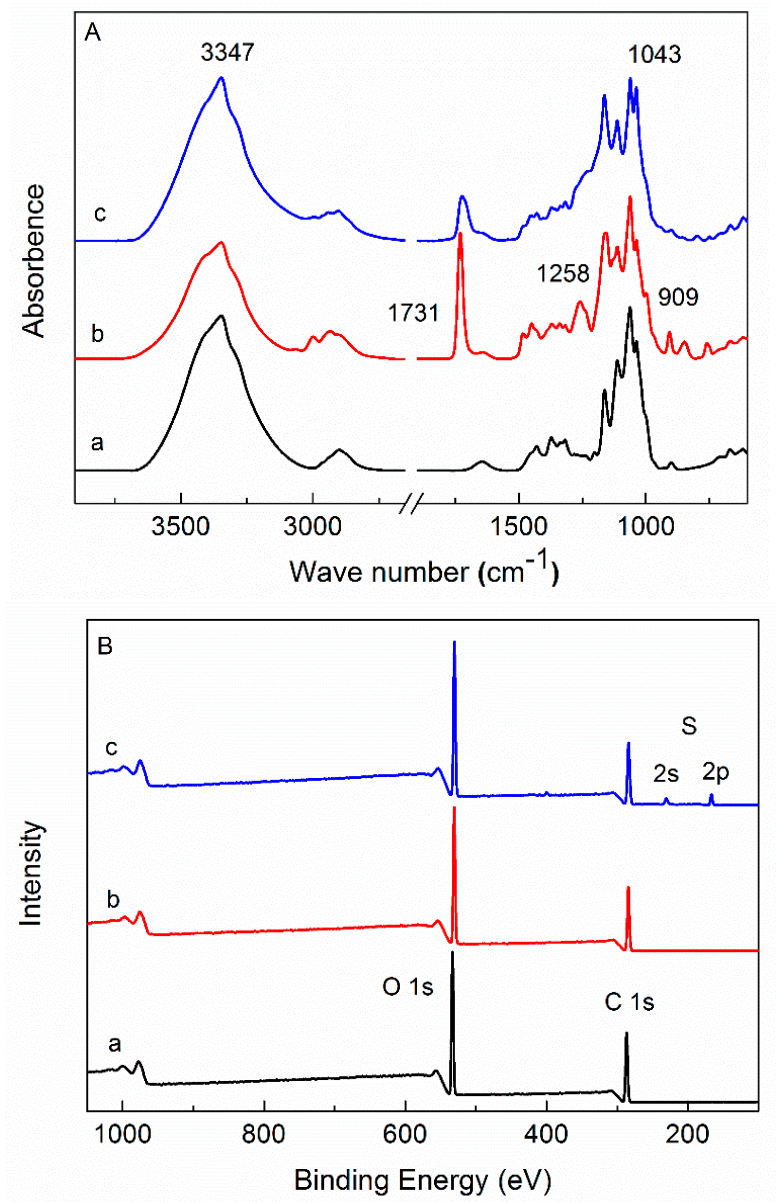

Figure 1. (A) Micro-FTIR spectra of (a) CMS (microcrystalline cellulose), (b) CGG cellulose microspheres grafted with GMA (glycidyl methacrylate)), and (c) CGS; (B) XPS (X-ray photoelectron spectroscopy) diagram of (a) CMS, (b) CGG (degree of grafting (DG) $=63 \%$ ), and (c) CGS-II.

The XPS patterns of the CMS, CGG and CGS are shown in Figure 1B. For the CMS, only peaks of $\mathrm{C} 1 \mathrm{~s}$ and $\mathrm{O}$ 1s could be observed in XPS. Since the elements in the PGMA were similar with those of the CMS, no new peaks beside $\mathrm{C} 1 \mathrm{~s}$ and $\mathrm{O} 1 \mathrm{~s}$ were observed in the CGG. In contrast, after sulfonation and protonation, new peaks of S $2 \mathrm{~s}$ and S 2p at 229 and $165.5 \mathrm{eV}$, respectively, appeared, and it further identified the successful sulfonation; the XPS analysis agreed well with the micro-FTIR results.

\subsubsection{SEM Observation}

The morphology of the adsorbent is of great importance for the adsorption properties of microspheres. SEM images of the CMS, CGG and CGS are shown in Figure 2. For the CMS, the average diameter was about $230 \mu \mathrm{m}$. For the grafting of the PGMA onto the CMS, the diameter of the CGG increased to $340 \mu \mathrm{m}$, and it had a DG value of $63 \%$, indicating the grafting of the PGMA on the surface of the CMS. Finally, the diameter of the microspheres was increased to $390 \mu \mathrm{m}$ after sulfonation and protonation, and the surface of the CGS became rougher than that of the CGG. This was attributed to the chemical modification of the PGMA on the surface of the CGG. The change in the SEM images of the microspheres after the grafting, the sulfonation, and the protonation also confirmed the success of the modification process from the CMS to the CGS. After the grafting and chemical 
modification, the resultant microsphere still kept its spherical morphology, which showed its potential use in column adsorption [29].

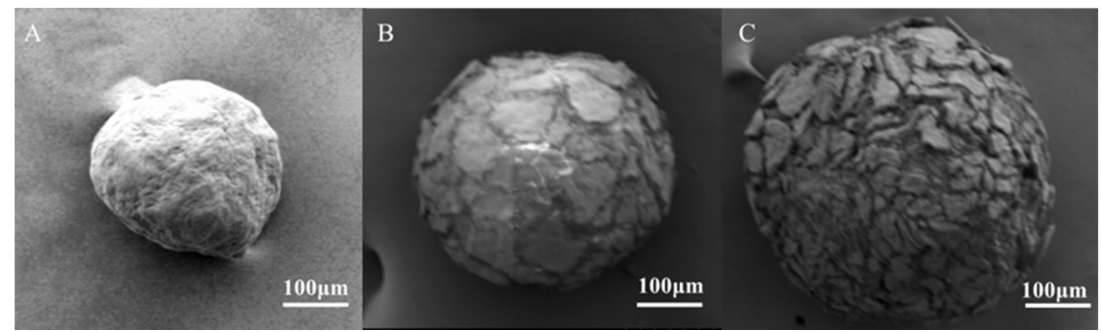

Figure 2. SEM images of different samples. (A) CMS; (B) CGG (DG = 63\%); (C) CGS-II.

\subsection{Adsorption Performance of $\mathrm{Li}^{+}$onto CGS Adsorbents}

Both the batch and column adsorption performance of $\mathrm{Li}^{+}$onto the resultant CGS adsorbents were investigated for evaluating the adsorption capacity of the CGS adsorbent for $\mathrm{Li}^{+}$.

\subsubsection{Adsorption Kinetics and Isotherms}

It is very important to study the adsorption kinetics for practical use. As shown in Figure 3A, a fast adsorption process in the first $30 \mathrm{~min}$ was observed for both CGS-I and CGS-II. Then, a slow process occurred from 30 to $40 \mathrm{~min}$, and finally both CGS-I and CGS-II reached an adsorption equilibrium within $40 \mathrm{~min}$, showing a similar behavior when the CGS adsorbents were applied to ionic liquids adsorption [27]. Compared with existing Lithium adsorbents, the CGS was much faster than $\mathrm{H}_{2} \mathrm{TiO}_{3}$, some ion-sieves [8,33], and the DIAION SK1B ion exchange resin (see Table 1), which is very important for the practical application of adsorbents. The data of the kinetics curves were fitted by the pseudo-first-order and pseudo-second-order models, which are shown in Equations (3) and (4), respectively:

$$
\begin{gathered}
\log \left(q-q_{t}\right)=\log q-\frac{k_{1}}{2.303} t \\
\frac{t}{q_{t}}=\frac{1}{q} t+\frac{1}{q^{2} k_{2}}
\end{gathered}
$$

where $q_{t}$ and $q$ are the $\mathrm{Li}^{+}$uptakes at the time $t$ and equilibrium, respectively; $k_{1}\left(\mathrm{~min}^{-1}\right)$ and $k_{2}$ $\left(\mathrm{g} \mathrm{mg}^{-1} \mathrm{~min}^{-1}\right.$ ) are the rate constants of the pseudo-first-order and the pseudo-second-order model, respectively. Huang Y. et al. [34] pointed out that $q$ is not a constant during the adsorption process as the concentration of the solution changes. Here, an initial solution with a high concentration was used in the adsorption kinetics study, and the concentration decreased to less than $10 \%$ during the experiment, which could be ignored. Therefore, $q$ values are considered to be constant in this work.

The linear fits of the kinetic data are shown in Figure 3B, and the fitting results are presented in Table 2. For both CGS-I and CGS-II, the pseudo-second-order model gave better fitting parameters compared to those of the pseudo-first-order model. Furthermore, the $q$ values of CGS-I and CGS-II obtained from the pseudo-second-order model were closer to the experimental equilibrium value on the curve, indicating that the rate-limiting step could be chemical sorption involving the exchange of ion between the CGS and the $\mathrm{Li}^{+}$[35]. In order to reach an adsorption equilibrium, $12 \mathrm{~h}$ was used as the contact time in the experiment. 

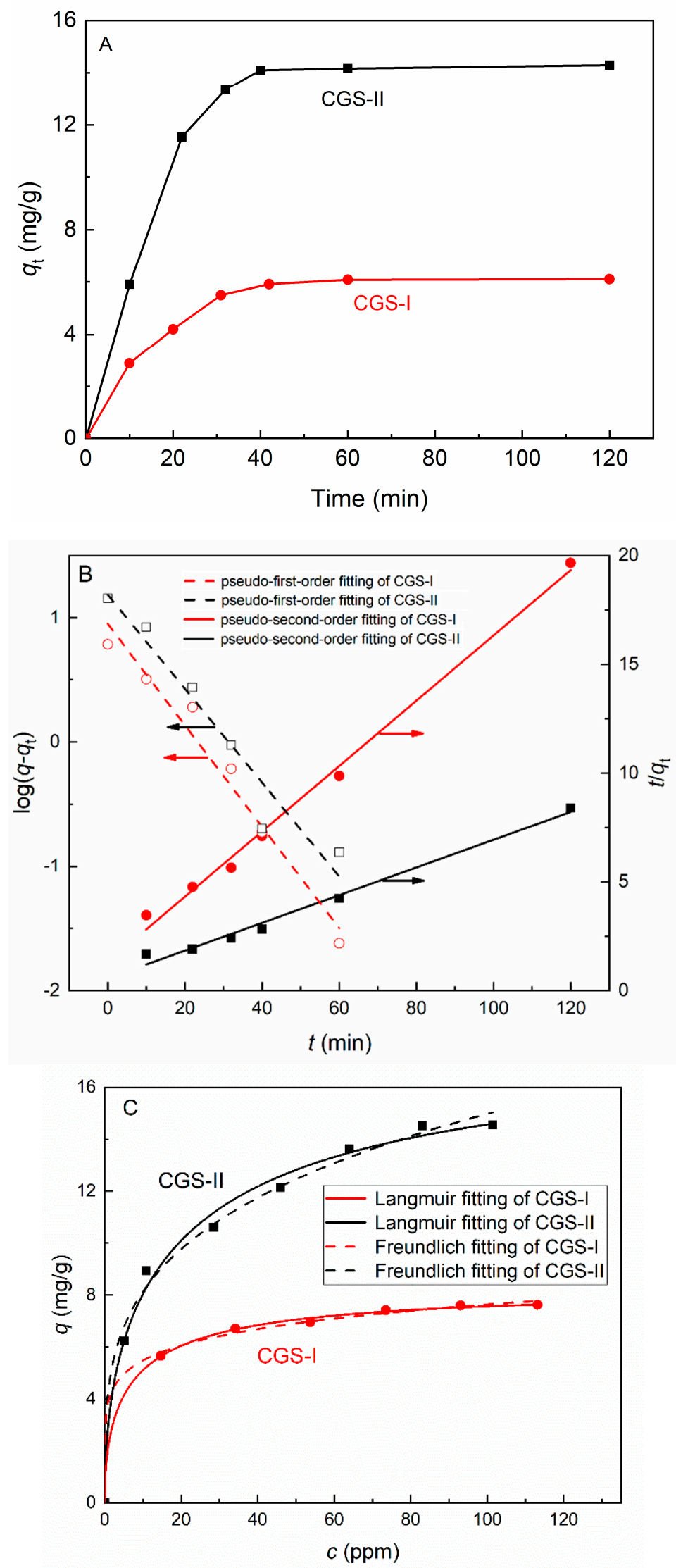

Figure 3. (A) Adsorption kinetics of the CGS adsorbent for $\mathrm{Li}^{+}$adsorption; (B) linear fit of the kinetic data for CGS-I and CGS-II; and (C) adsorption isotherm of the CGS adsorbent for $\mathrm{Li}^{+}$adsorption. 
Table 1. Time to reach equilibrium and maximum adsorption capacity for some $\mathrm{Li}^{+}$adsorbents.

\begin{tabular}{cccc}
\hline Adsorbents & Equilibrium Time & $\begin{array}{c}\text { Maximum Adsorption } \\
\text { Capacity (mg/g) }\end{array}$ & Ref \\
\hline $\mathrm{H}_{2} \mathrm{TiO}_{3}$ & $10 \mathrm{~h}$ & 32.6 & {$[10]$} \\
Iron-Doped Manganese Oxides & $6 \mathrm{~h}$ & 28 & {$[33]$} \\
$\mathrm{H}_{1.6} \mathrm{Mn}_{1.6} \mathrm{O}_{4} /$ poly(acrylonitrile) & - & 10.3 & {$[36]$} \\
Lewatit K2629/TP 207/TP 208 resin & $<30 \mathrm{~min}$ & $1.23-2.54$ & {$[37]$} \\
DIAION SK1B resin & $3 \mathrm{~h}$ & 0.23 & This work \\
CGS & $40 \mathrm{~min}$ & 16.0 & This work \\
\hline
\end{tabular}

Table 2. Kinetic results of CGS-I and CGS-II for $\mathrm{Li}^{+}$adsorption $(\mathrm{LiCl}, \mathrm{pH}=10)$.

\begin{tabular}{|c|c|c|c|c|c|c|}
\hline \multirow{2}{*}{ Sample } & \multicolumn{3}{|c|}{ Pseudo-First-Order } & \multicolumn{3}{|c|}{ Pseudo-Second-Order } \\
\hline & $k_{1}\left(\min ^{-1}\right)$ & $q(\mathrm{mg} / \mathrm{g})$ & $\mathbf{R}^{2}$ & $k_{2}\left(\mathrm{~g} \mathrm{mg}^{-1} \mathrm{~min}^{-1}\right)$ & $q(\mathrm{mg} / \mathrm{g})$ & $\mathbf{R}^{2}$ \\
\hline CGS-I & 16.8 & 7.84 & 0.948 & 0.0017 & 6.72 & 0.990 \\
\hline CGS-II & 20.7 & 20.1 & 0.970 & 0.0082 & 15.6 & 0.987 \\
\hline
\end{tabular}

The adsorption isotherm curves of the CGS are presented in Figure 3C. Two typical isotherm models, Langmuir and Freundlich, expressed as Equations (5) and (6), respectively, were used to fit the data, where $q(\mathrm{mg} / \mathrm{g})$ is the $\mathrm{Li}^{+}$uptake at the corresponding $\mathrm{Li}^{+}$concentration $c$ in the solution and $q_{e}$ is the adsorption capacity. $K_{L}$ and $K(\mathrm{~L} / \mathrm{mg})$ represent the Langmuir and Freundlich constants, respectively, and in the Freundlich model, $1 / n$ represents a coefficient connected with heterogeneity.

$$
\text { Langmuir model : } \frac{c}{q}=\frac{c}{q_{e}}+\frac{1}{K_{L} q_{e}}
$$

$$
\text { Freundlich model : } q=K c^{\frac{1}{n}}
$$

As shown in Table 3, when fitted by the Langmuir model, both CGS-I and CGS-II had much higher $\mathrm{R}^{2}$ values, indicating that the adsorption of $\mathrm{Li}^{+}$corresponded to a saturated monolayer of cations [38] on the surface of the CGS. The adsorption capacities of CGS-I and CGS-II were 8.02 and $16.0 \mathrm{mg} / \mathrm{g}$, respectively, which was relatively high compared to the other $\mathrm{Li}^{+}$adsorbents (see Table 1). In addition, for CGS-II, a removal of $6 \mathrm{mg} / \mathrm{g}$ of $\mathrm{Li}^{+}$was still obtained at a low initial concentration of $\mathrm{Li}^{+}(11 \mathrm{mg} / \mathrm{L})$, which demonstrated a potential use in the separation of $\mathrm{Li}^{+}$under low concentrations. Similar isotherm adsorption behavior was also observed in the lithium manganese oxide adsorbent [14]. Furthermore, the adsorption capacity increased with increasing the content of sulfonic acid group in the CGS.

Table 3. Sample information and isotherm results of CGS-I and CGS-II for $\mathrm{Li}^{+}$adsorption ( $\mathrm{LiCl}$, $\mathrm{pH}=10$ ).

\begin{tabular}{cccccc}
\hline \multirow{2}{*}{ Sample } & S Content & \multicolumn{2}{c}{ Langmuir } & \multicolumn{2}{c}{ Freundlich } \\
\cline { 2 - 6 } & $\mathbf{\%}$ & $\mathbf{R}^{\mathbf{2}}$ & $\boldsymbol{q}_{\mathbf{e}}(\mathbf{m g} / \mathbf{g})$ & $\mathbf{R}^{\mathbf{2}}$ & $\mathbf{1 / n}$ \\
\hline CGS-I & 5.7 & 0.999 & 8.02 & 0.938 & 0.140 \\
\hline CGS-II & 8.0 & 0.996 & 16.0 & 0.988 & 0.287 \\
\hline
\end{tabular}

\subsubsection{Effect of Solution $\mathrm{pH}$}

The $\mathrm{pH}$ of the solution is an important parameter for the adsorption properties of $\mathrm{Li}^{+}$[17]. As shown in Figure 4, the $\mathrm{Li}^{+}$uptake decreased at $\mathrm{pH}$ values below 4, which was attributed to the competition of $\mathrm{H}^{+}$against $\mathrm{Li}^{+}$for the active sites on the CGS adsorbent. The $\mathrm{Li}^{+}$uptake also decreased when the $\mathrm{pH}$ increased to 11.2 due to the competition between $\mathrm{Na}^{+}$and $\mathrm{Li}^{+}$. Furthermore, at a $\mathrm{pH}$ above $13, \mathrm{OH}^{-}$destroys the structure of cellulose microspheres [39], so adsorption under a higher $\mathrm{pH}$ 
was not tested. However, it should be noted that the CGS had a good adsorption property in a wide $\mathrm{pH}$ range from 4 to 10, indicating its potential for usage in the separation of $\mathrm{Li}^{+}$.

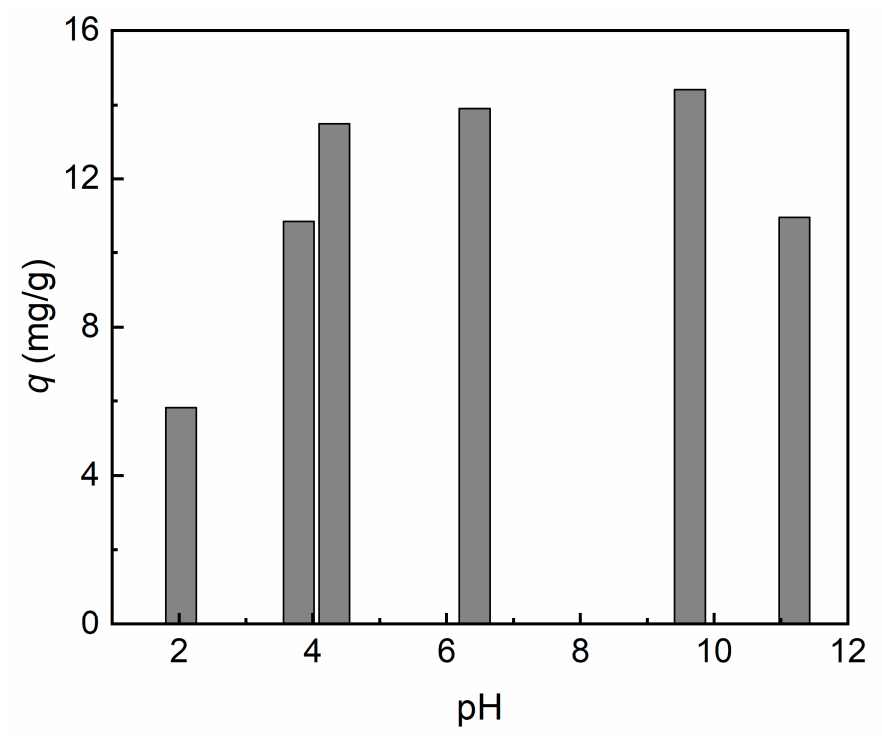

Figure 4. Equilibrium $\mathrm{Li}^{+}$uptake of CGS-II under different $\mathrm{pH}$ levels.

\subsubsection{Effect of Different Cations and Anions of Salts}

$\mathrm{Na}^{+}$and $\mathrm{K}^{+}$, which are common coexisting ions with $\mathrm{Li}^{+}$in aqueous solutions, were both chosen as the models to investigate the influence of the cations on the adsorption of $\mathrm{Li}^{+}$onto the CGS. As shown in Figure 5A, the adsorption of $\mathrm{Li}^{+}$decreased with the increase of concentration of $\mathrm{Na}^{+}$or $\mathrm{K}^{+}$. This was attributed to the competition between $\mathrm{Li}^{+}$and $\mathrm{Na}^{+}$or $\mathrm{K}^{+}$. With the increase of size of ions, the effect on adsorption uptake of $\mathrm{Li}^{+}$increased. The effect of different anions is shown in Figure $5 \mathrm{~B}$ by using various lithium salts such as $\mathrm{LiCl}, \mathrm{Li}_{2} \mathrm{SO}_{4}, \mathrm{LiNO}_{3}, \mathrm{LiSCN}$. Herein, we set the relative capacity, using $\mathrm{LiCl}$ as an $\mathrm{Li}^{+}$salt, as $100 \%$. There was no obvious difference in the adsorption capacities when using $\mathrm{LiCl}, \mathrm{Li}_{2} \mathrm{SO}_{4}, \mathrm{LiNO}_{3}$ and $\mathrm{LiSCN}$ as $\mathrm{Li}^{+}$salts. The influence of cations and anions on the adsorption demonstrated a cation-exchange interaction between $\mathrm{Li}^{+}$and the CGS during the adsorption.

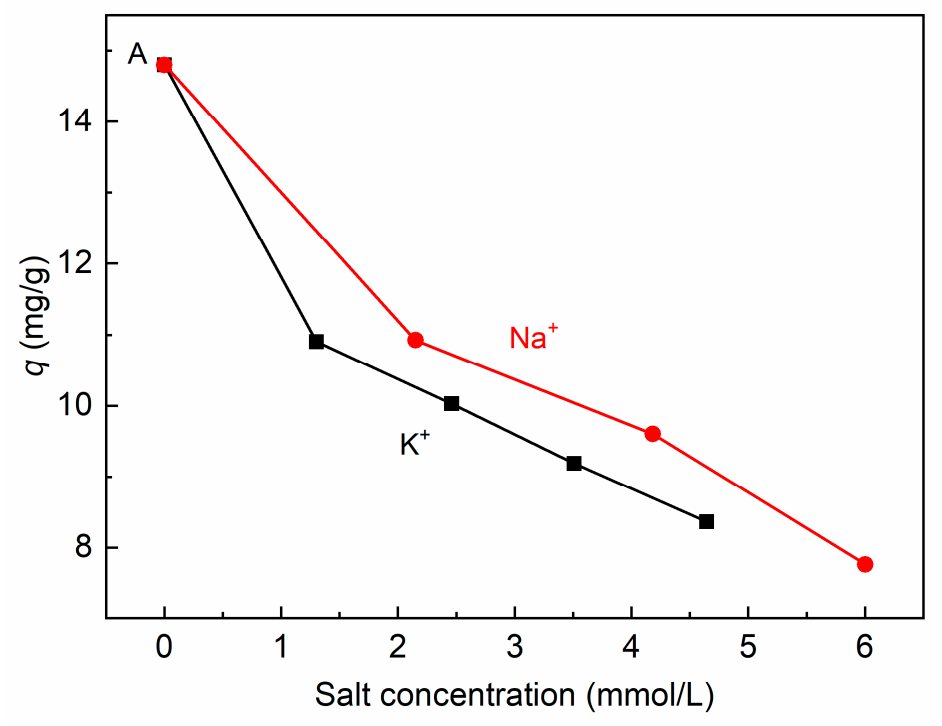

Figure 5. Cont. 


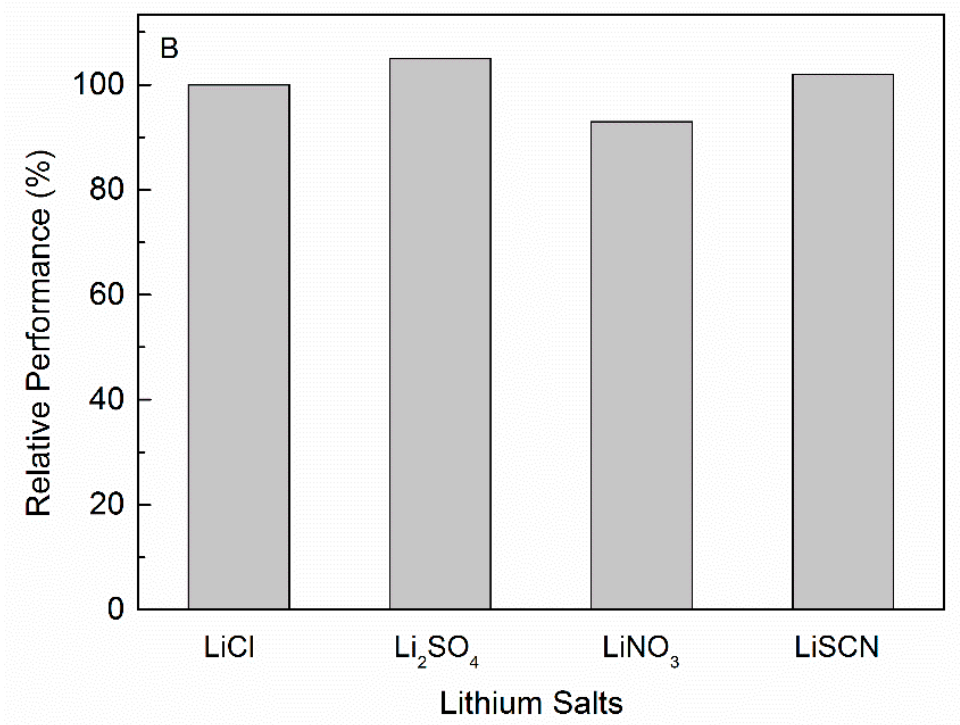

Figure 5. (A) Influence of different cations on the $\mathrm{Li}^{+}$adsorption performance of the CGS; (B) Influence of various lithium salts on the $\mathrm{Li}^{+}$adsorption performance of the CGS.

\subsubsection{Adsorption Mechanism and the Regeneration of CGS Adsorbents}

In order to further study the adsorption mechanism of the CGS towards $\mathrm{Li}^{+}$, the XPS of the CGS before and after the $\mathrm{Li}^{+}$adsorption as well as after the desorption were measured. As shown in Figure 6A, a peak around binding energy (B.E.) of $55.6 \mathrm{eV}$ occurred after the adsorption of $\mathrm{Li}^{+}$, which was attributed to the $\mathrm{Li} 1$ s group [40]. Moreover, the B.E. of the $\mathrm{O}$ and $\mathrm{S}$ groups in the CGS did not change after the adsorption of $\mathrm{Li}^{+}$, indicating that no complexation between $\mathrm{O}$ or $\mathrm{S}$ and $\mathrm{Li}^{+}$ occurred during the adsorption. After desorption by $1 \mathrm{~mol} / \mathrm{L} \mathrm{HCl}$, the peak around the B.E. of $55.6 \mathrm{eV}$ disappeared. No new peaks appeared because $\mathrm{H}^{+}$was exchanged onto the $-\mathrm{SO}_{3}{ }^{-}$group. All the above results confirmed the cation-exchange mechanism for the adsorption of $\mathrm{Li}^{+}$onto the CGS.
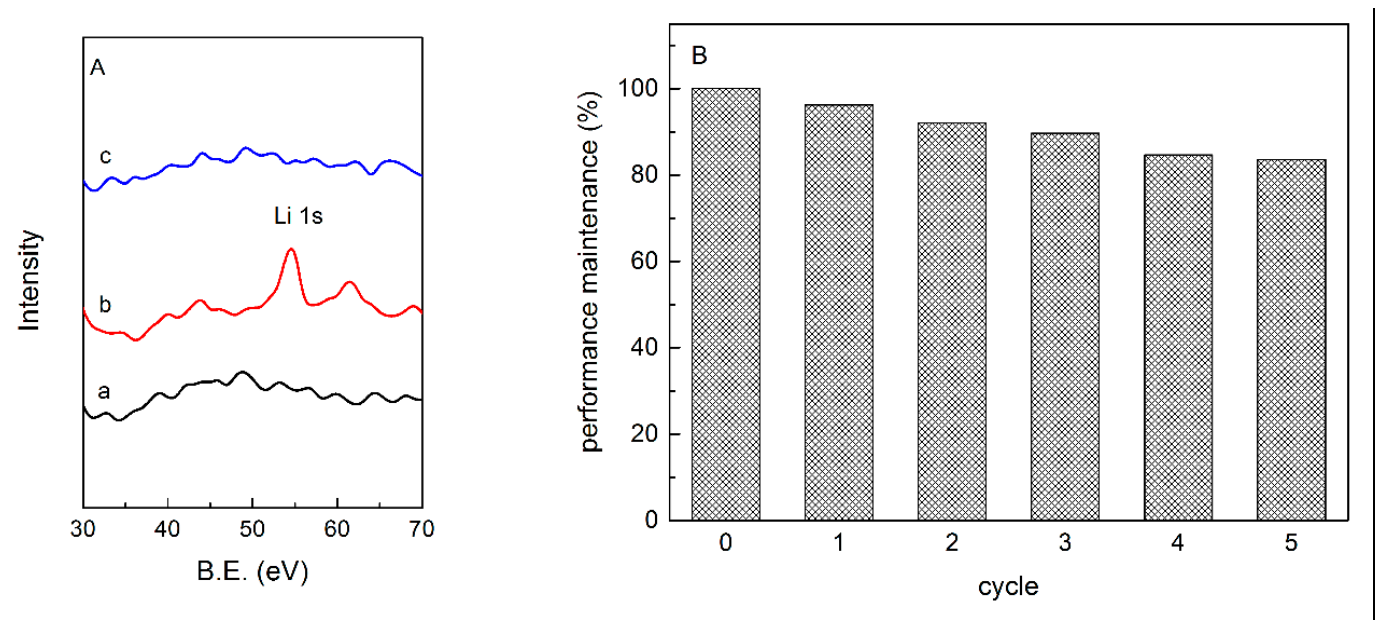

Figure 6. (A) XPS of CGS-II under different conditions. (a) Fresh CGS-II; (b) after the adsorption of $\mathrm{Li}^{+}$; (c) after desorption. (B) Adsorption performance of CGS-II after different times of regeneration by $\mathrm{HCl}$.

In practical usage, adsorbents should have a good reusability. The as-prepared CGS-II was tested by using five consecutive adsorption-desorption cycles. As shown in Figure 6B, the adsorption performance declined slowly to $89 \%$ in the first three cycles. However, CGS-II still maintained $83 \%$ of its performance after five cycles. It was illustrated that the resultant CGS had a good stability during the adsorption and desorption process and could be easily reused. 


\subsubsection{Column Adsorption Study of CGS Adsorbents for $\mathrm{Li}^{+}$}

To simulate a practical application, a primary column adsorption experiment was carried out, and the results are shown in Figure 7. The breakthrough curve follows the typical S-shape curve [41]. In the first $200 \mathrm{~min}$, no $\mathrm{Li}^{+}$signal was detected by ICP-AES, which meant that almost all the $\mathrm{Li}^{+}$was adsorbed by the CGS column. The breakthrough $\left(C_{t} / C_{i}=10 \%\right)$ occurred at $325 \mathrm{~min}$, the saturation $\left(C_{t} / C_{i}=90 \%\right)$ occurred at $456 \mathrm{~min}$, and equilibrium $\left(C_{\mathrm{t}} / C_{\mathrm{i}}=100 \%\right)$ occurred at about $600 \mathrm{~min}$ during the adsorption of $\mathrm{Li}^{+}$onto CGS-II. Correspondingly, the $\mathrm{Li}^{+}$adsorption capacities of CGS-II at breakthrough time, saturation time and equilibrium time were determined to be $9.80,11.5$ and $11.8 \mathrm{mg} / \mathrm{g}$, respectively. The equilibrium adsorption capacity agreed well with that obtained in the batch experiment of CGS-II. The desorption curve shows a sharp elution peak. After a period of time, $80 \%(9.37 \mathrm{mg} / \mathrm{g})$ of the adsorbed $\mathrm{Li}^{+}$could be desorbed, showing a reasonable agreement with the regeneration experiment results. It is worth mentioning that $98 \%$ of the desorption capacity was achieved in $10 \mathrm{~min}$, which indicates the good enrichment effect of CGS-II adsorbent towards $\mathrm{Li}^{+}$in the aqueous solution.
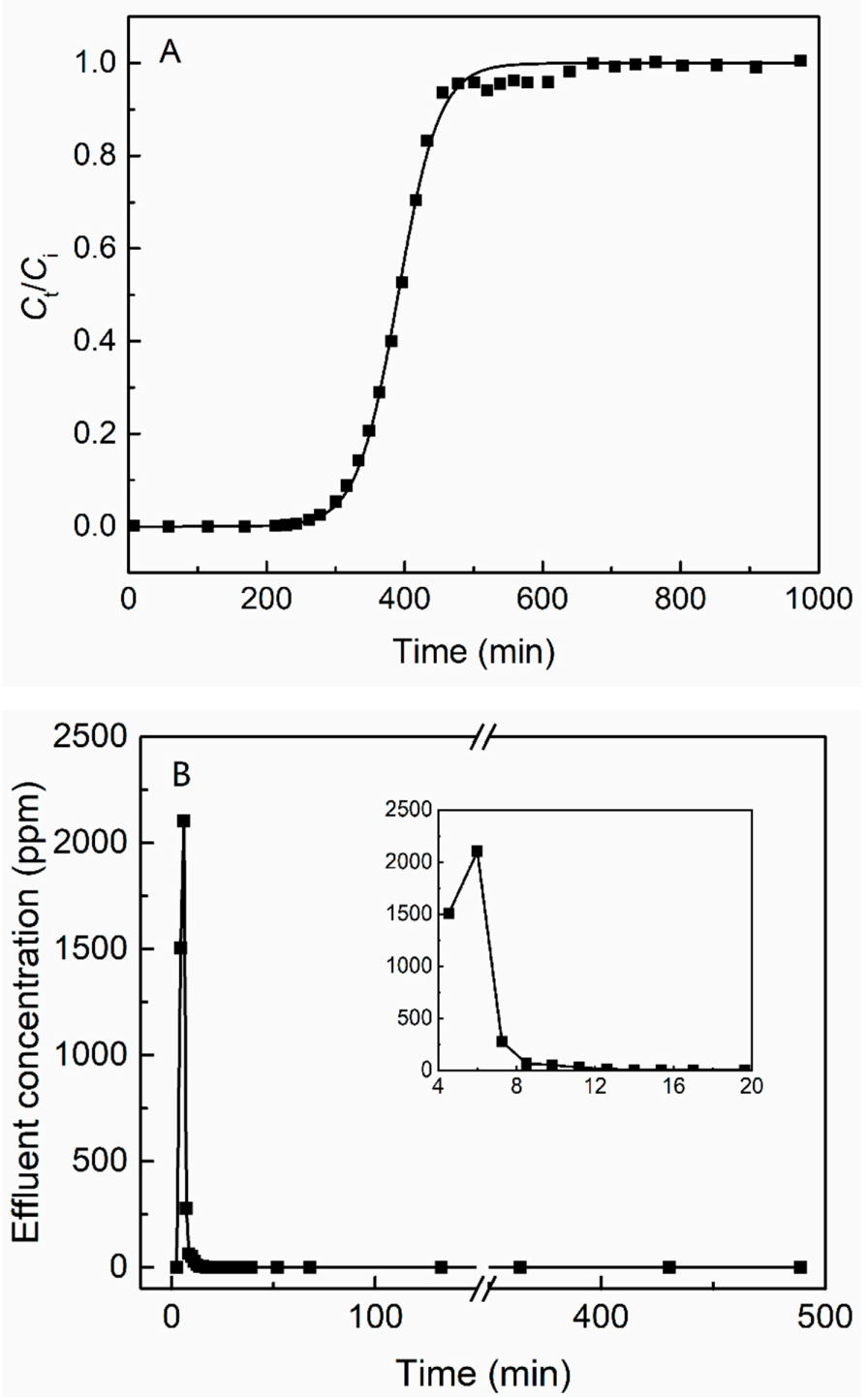

Figure 7. (A) Breakthrough curve of adsorption of $\mathrm{Li}^{+}$onto CGS-II. (B) Desorption curve of $\mathrm{Li}^{+}$from CGS-II. Inset: a magnification of the first $20 \mathrm{~min}$. 


\section{Conclusions}

A cellulose microsphere-adsorbent that contained sulfonic acid groups for $\mathrm{Li}^{+}$- the CGS-was successfully prepared by the pre-irradiation-induced emulsion grafting of GMA onto a CMS, followed by sulfonation and protonation. The adsorption behavior of $\mathrm{Li}^{+}$onto the CGS was well investigated. The adsorption process of $\mathrm{Li}^{+}$onto the CGS had faster adsorption kinetics than commercial cation exchange resin and some ion sieves reported in the literatures. The adsorption isotherm agreed well with the Langmuir model, with a lithium adsorption capacity of $16.0 \mathrm{mg} / \mathrm{g}$ for CGS-II. The CGS adsorbents had good adsorption properties in a wide $\mathrm{pH}$ range from 4 to 10 , which covers the $\mathrm{pH}$ of brine. The addition of $\mathrm{Na}^{+}$and $\mathrm{K}^{+}$led to a decrease in the adsorption capacity of $\mathrm{Li}^{+}$due to the competition for the active sites, while different anions had little influence on adsorption, indicating that the cation-exchange mechanism was dominant in the adsorption of $\mathrm{Li}^{+}$onto the CGS. The CGS could be easily regenerated and reused in five adsorption-desorption cycles, and the column adsorption study showed the quick adsorption and desorption of $\mathrm{Li}^{+}$, which illustrates a potential application in the separation of $\mathrm{Li}^{+}$ions from an aqueous solution. Consequently, this work provides a feasible and low cost route for $\mathrm{Li}^{+}$removal.

Author Contributions: Conceptualization, J.P. and M.Z.; investigation, C.X., T.Y. and J.L.; data curation, C.X. and T.Y.; writing — original draft preparation, C.X. and T.Y.; writing—review and editing, J.P., L.Z. and M.Z. All authors have read and agreed to the published version of the manuscript.

Funding: The research and the APC were financially supported by the National Natural Science Foundation of China (NNSFC, Project No. U1430234).

Acknowledgments: We would like to give thanks to Min Xu for his help in methodology, and Dong Han for his help in reviewing the manuscript.

Conflicts of Interest: The authors declare no conflicts of interest.

\section{References}

1. Ebensperger, A.; Maxwell, P.; Moscoso, C. The Lithium Industry: Its Recent Evolution and Future Prospects. Resour. Policy 2005, 30, 218-231. [CrossRef]

2. Vikstrom, H.; Davidsson, S.; Hook, M. Lithium Availability and Future Production Outlooks. Appl. Energy 2013, 110, 252-266. [CrossRef]

3. Bradshaw, A.M.; Hamacher, T.; Fischer, U. Is Nuclear Fusion a Sustainable Energy Form? Fusion Eng. Des. 2011, 86, 2770-2773. [CrossRef]

4. Zhu, G.R.; Wang, P.; Qi, P.F.; Gao, C.J. Adsorption and Desorption Properties of $\mathrm{Li}^{+}$on PVC- $\mathrm{H}_{1.6} \mathrm{Mn}_{1.6} \mathrm{O}_{4}$ Lithium Ion-Sieve Membrane. Chem. Eng. J. 2014, 235, 340-348. [CrossRef]

5. Zhou, Z; Qin, W.; Fei, W. Extraction Equilibria of Lithium with Tributyl Phosphate in Three Diluents. J. Chem. Eng. Data 2011, 56, 3518-3522. [CrossRef]

6. Zhou, Z.Y.; Qin, W.; Liang, S.K.; Tan, Y.Z.; Fei, W.Y. Recovery of Lithium Using Tributyl Phosphate in Methyl Isobutyl Ketone and $\mathrm{FeCl}_{3}$. Ind. Eng. Chem. Res. 2012, 51, 12926-12932. [CrossRef]

7. An, J.W.; Kang, D.J.; Tran, K.T.; Kim, M.J.; Lim, T.; Tran, T. Recovery of Lithium from Uyuni Salar Brine. Hydrometallurgy 2012, 117, 64-70. [CrossRef]

8. Lee, J.; Yu, S.H.; Kim, C.; Sung, Y.E.; Yoon, J. Highly Selective Lithium Recovery from Brine Using a Lambda-MnO 2 -Ag Battery. Phys. Chem. Chem. Phys. 2013, 15, 7690-7695. [CrossRef]

9. Ryu, T.; Ryu, J.C.; Shin, J.; Lee, D.H.; Kim, Y.H.; Chung, K.S. Recovery of Lithium by an Electrostatic Field-Assisted Desorption Process. Ind. Eng. Chem. Res. 2013, 52, 13738-13742. [CrossRef]

10. Chitrakar, R.; Makita, Y.; Ooi, K.; Sonoda, A. Lithium Recovery from Salt Lake Brine by $\mathrm{H}_{2} \mathrm{TiO}_{3}$. Dalton Trans. 2014, 43, 8933-8939. [CrossRef]

11. Luo, X.B.; Guo, B.; Luo, J.M.; Deng, F.; Zhang, S.Y.; Luo, S.L.; Crittenden, J. Recovery of Lithium from Wastewater Using Development of Li Ion-Imprinted Polymers. ACS Sustain. Chem. Eng. 2015, 3, 460-467. [CrossRef] 
12. Recepoglu, Y.K.; Kabay, N.; Yilmaz-Ipek, I.; Arda, M.; Yoshizuka, K.; Nishihama, S.; Yukel, M. Equilibrium and Kinetic Studies on Lithium Adsorption from Geothermal Water by Lambda-MnO 2 . Solvent Extr. Ion Exch. 2017, 35, 221-231. [CrossRef]

13. Kim, J.; Oh, S.; Kwak, S.Y. Magnetically Separable Magnetite-Lithium Manganese Oxide Nanocomposites as Reusable Lithium Adsorbents in Aqueous Lithium Resources. Chem. Eng. J. 2015, 281, 541-548. [CrossRef]

14. Ryu, T.; Shin, J.; Lee, D.H.; Ryu, J.; Park, I.; Hong, H.; Kim, B.G.; Lee, J.B.; Huh, Y.S.; Chung, K.S. Improvement of Lithium Adsorption Capacity of Porous Cylinder-Type Lithium Manganese Oxide through Introduction of Additive. Mater. Chem. Phys. 2015, 167, 225-230. [CrossRef]

15. Chitrakar, R.; Kanoh, H.; Miyai, Y.; Ooi, K. Recovery of Lithium from Seawater using Manganese Oxide Adsorbent $\left(\mathrm{H}_{1.6} \mathrm{Mn}_{1.6} \mathrm{O}_{4}\right)$ Derived from $\mathrm{Li}_{1.6} \mathrm{Mn}_{1.6} \mathrm{O}_{4}$. Ind. Eng. Chem. Res. 2001, 40, 2054-2058. [CrossRef]

16. Chung, K.S.; Lee, J.C.; Kim, W.K.; Kim, S.B.; Cho, K.Y. Inorganic Adsorbent Containing Polymeric Membrane Reservoir for the Recovery of Lithium from Seawater. J. Membrane Sci. 2008, 325, 503-508. [CrossRef]

17. Xiao, J.L.; Nie, X.Y.; Sun, S.Y.; Song, X.F.; Li, P.; Yu, J.G. Lithium Ion Adsorption-Desorption Properties on Spinel $\mathrm{Li}_{4} \mathrm{Mn}_{5} \mathrm{O}_{12}$ and pH-Dependent Ion-Exchange Model. Adv. Powder Technol. 2015, 26, 589-594. [CrossRef]

18. Ma, L.W.; Chen, B.Z.; Chen, Y.; Shi, X.C. Preparation, Characterization and Adsorptive Properties of Foam-Type Lithium Adsorbent. Mesoporous Mesoporous Mat. 2011, 142, 147-153. [CrossRef]

19. Xiao, G.P.; Tong, K.F.; Zhou, L.S.; Xiao, J.L.; Sun, S.Y.; Li, P.; Yu, J.G. Adsorption and Desorption Behavior of Lithium Ion in Spherical PVC-MnO 2 Ion Sieve. Ind. Eng. Chem. Res. 2012, 51, 10921-10929. [CrossRef]

20. Kang, H.L.; Liu, R.G.; Huang, Y. Cellulose Derivatives and Graft Copolymers as Blocks for Functional Materials. Polym. Int. 2013, 62, 338-344. [CrossRef]

21. Kongkaoroptham, P.; Piroonpan, T.; Hemvichian, K.; Suwanmala, P.; Rattanasakulthong, W.; Pasanphan, W. Poly(Ethylene Glycol) Methyl Ether Methacrylate-Graft-Chitosan Nanoparticles as a Biobased Nanofiller for a Poly(Lactic Acid) Blend: Radiation-Induced Grafting and Performance Studies. J. Appl. Polym. Sci. 2015, 132. [CrossRef]

22. Munoz-Munoz, F.; Bucio, E.; Magarinos, B.; Concheiro, A.; Alvarez-Lorenzo, C. Temperature- and $\mathrm{pH}$-Sensitive IPNs Grafted onto Polyurethane by Gamma Radiation for Antimicrobial Drug-Eluting Insertable Devices. J. Appl. Polym. Sci. 2014, 131. [CrossRef]

23. Guin, J.P.; Bhardwaj, Y.K.; Varshney, L. Radiation Grafting: A Voyage from Bio-Waste Corn Husk to an Efficient Thermostable Adsorbent. Carbohydr. Polym. 2018, 183, 151-164. [CrossRef]

24. Wojnarovits, L.; Foldvary, C.M.; Takacs, E. Radiation-Induced Grafting of Cellulose for Adsorption of Hazardous Water Pollutants: A Review. Radiat. Phys. Chem. 2010, 79, 848-862. [CrossRef]

25. Yu, T.; Liu, S.; Xu, M.; Peng, J.; Li, J.; Zhai, M. Synthesis of Novel Aminated Cellulose Microsphere Adsorbent for Efficient Cr(VI) Removal. Radiat. Phys. Chem. 2016, 125, 94-101. [CrossRef]

26. Barsbay, M.; Kavakh, P.A.; Tilki, S.; Kavakh, C.; Guven, O. Porous Cellulosic Adsorbent for the Removal of $\mathrm{Cd}$ (II), $\mathrm{Pb}$ (II) and Cu(II) Ions from Aqueous Media. Radiat. Phys. Chem. 2018, 142, 70-76. [CrossRef]

27. Xu, M.; Ao, Y.; Wang, S.; Peng, J.; Li, J.; Zhai, M. Efficient Adsorption of 1-Alkyl-3-Methylimidazolium Chloride Ionic Liquids onto Modified Cellulose Microspheres. Carbohydr. Polym. 2015, 128, 171-178. [CrossRef]

28. Sokker, H.H.; Badawy, S.M.; Zayed, E.M.; Eldien, F.A.N.; Farag, A.M. Radiation-Induced Grafting of Glycidyl Methacrylate onto Cotton Fabric Waste and its Modification for Anchoring Hazardous Wastes from their Solutions. J. Hazard. Mater. 2009, 168, 137-144. [CrossRef]

29. Dong, Z.; Liu, J.; Yuan, W.; Yi, Y.; Zhao, L. Recovery of Au(III) by Radiation Synthesized Aminomethyl Pyridine Functionalized Adsorbents Based on Cellulose. Chem. Eng. J. 2016, 283, 504-513. [CrossRef]

30. Alberti, A.; Bertini, S.; Gastaldi, G.; Iannaccone, N.; Macciantelli, D.; Torri, G.; Vismara, E. Electron beam Irradiated Textile Cellulose Fibres. ESR Studies and Derivatisation with Glycidyl Methacrylate (GMA). Eur. Polym. J. 2005, 41, 1787-1797. [CrossRef]

31. Chen, I.; Xu, C.; Peng, J.; Han, D.; Liu, S.; Zhai, M. Novel Functionalized Cellulose Microspheres for Efficient Separation of Lithium Ion and Its Isotopes: Synthesis and Adsorption Performance. Molecules 2019, 24, 2762. [CrossRef] [PubMed]

32. Seko, N.; Bang, L.T.; Tamada, M. Syntheses of Amine-Type Adsorbents with Emulsion Graft Polymerization of Glycidyl Methacrylate. Nucl. Instr. Meth. Phys. Res. B 2007, 265, 146-149. [CrossRef] 
33. Chitrakar, R.; Makita, Y.; Ooi, K.; Sonoda, A. Synthesis of Iron-Doped Manganese Oxides with an Ion-Sieve Property: Lithium Adsorption from Bolivian Brine. Ind. Eng. Chem. Res. 2014, 53, 3682-3688. [CrossRef]

34. Huang, Y.; Farooq, M.U.; Lai, S.; Feng, X.; Sampranpiboon, P.; Wang, X.; Huang, W. Model Fitting of Sorption Kinetics Data: Misapplications Overlooked and their Rectifications. AIChE J. 2018, 64, 1793-1805. [CrossRef]

35. Ho, Y.S.; McKay, G. Pseudo-Second Order Model for Sorption Processes. Process. Biochem. 1999, 34, 451-465. [CrossRef]

36. Park, M.J.; Nisola, G.M.; Beltran, A.B.; Torrejos, R.E.C.; Seo, J.G.; Lee, S.; Kim, H.; Chung, W. Recyclable Composite Nanofiber Adsorbent for $\mathrm{Li}^{+}$Recovery from Seawater Desalination Retentate. Chem. Eng. J. 2014, 254, 73-81. [CrossRef]

37. Arroyo, F.; Morillo, J.; Usero, J.; Rosado, D.; Bakouri, H.E. Lithium Recovery from Desalination Brines using Specific Ion-Exchange Resins. Desalination 2019, 468, 114073. [CrossRef]

38. Eastoe, J.; Dalton, J.S. Dynamic Surface Tension and Adsorption Mechanisms of Surfactants at the Air-Water Interface. Adv Colloid Interfac. Sci. 2000, 85, 103-144. [CrossRef]

39. Knill, C.J.; Kennedy, J.F. Degradation of Cellulose under Alkaline Conditions. Carbohydr. Polym. 2003, 51, 281-300. [CrossRef]

40. Oswald, S. Binding Energy Referencing for XPS in Alkali Metal-Based Battery Materials Research (I): Basic Model Investigations. Appl. Surf. Sci. 2015, 351, 492-503. [CrossRef]

41. Chu, K.H. Improved Fixed Bed Models for Metal Biosorption. Chem. Eng. J. 2004, 97, 233-239. [CrossRef]

(C) 2020 by the authors. Licensee MDPI, Basel, Switzerland. This article is an open access article distributed under the terms and conditions of the Creative Commons Attribution (CC BY) license (http://creativecommons.org/licenses/by/4.0/). 